\title{
Evaluation System of Energy Efficiency Power Plant Benefit Based on the Analytic Hierarchy Process
}

\author{
Xiaodong $\mathrm{Xu}^{\mathrm{a}}$ \\ North China Electric Power University, Baoding 071000, China \\ a513178577@qq.com
}

Keywords: Energy efficiency power plant, analytic hierarchy process, evaluation index.

\begin{abstract}
In order to evaluate the effect of saving energy and reducing consumption of "Energy Efficiency Power Plant" projects in our province, thus better promote the realization of the goal of energy conservation and emission reduction, evaluation system of energy efficiency power plant benefit was put forward based on the analytic hierarchy process (AHP). This paper mainly illustrates the concept of energy efficiency power plant, and then through the AHP comprehensively weigh scale and characteristic of each kind project, evaluate the energy efficiency power plant, thereby overturn energy saving goal of various energy saving projects, and then energy saving goals are assigned to each energy-using enterprise, finally improve the enthusiasm of energy-saving reform, promote the realization of the goal of energy conservation and emissions reduction.
\end{abstract}

\section{Introduction}

With the rapid development of our economy, our country has become the world's energy consumption power. High energy consumption and low energy consumption efficiency have brought the serious environmental pollution; which make China face a lot of pressure on the goal of energy conservation and emissions reduction. According to the energy conservation planning requirements of the national development and reform commission (NDRC), by 2020, China's per ten thousand Yuan GDP energy consumption must be reduced from 2.68t in 2002 to $1.54 \mathrm{t}$ standard coal, 1.4 billion tons of standard coal with energy saving capacity are formed, A large part is done through the power saving. With the model of energy efficiency power plant, some policies methods are adopted, grid companies, the enthusiasm of power users and energy service companies are stimulated, by establishing effective evaluation methods and evaluation index, it can make the power grid companies and energy service enterprises has certain understanding to the project itself, and by adjusting the index to maximize the benefit of the project.

\section{The Definition of Energy Efficiency Power Plant}

Power demand side management (DSM) as an important part of China's energy strategy, and energy efficiency power plant project (EPP) as innovation model of DSM, which will be plays a more and more important role in energy saving in China in future. EPP is by adopting high efficient electricity equipment and products, optimize the electricity way and so on, forming package program of certain region, industry or enterprise energy-saving reform plan, and achieve the same purpose of new power plant, the reduction demand as the "virtual power plant" supplied power, achieve energy conservation and pollutant emission reduction. EPP concept vividly describes the role of DSM project, simplify selection and comparison of supply side and demand side resources, makes the DSM project with cost advantage are more likely to be included in selection range. Compared with new power plant construction, the EPP is obtained by optimizing power in original power supply system, no extra occupation of land, the consumption of resources such as coal; it has great social and economic benefits. 


\section{Model Introduction}

AHP (Analytic Hierarchy Process) is some more complex, vague problem decision-making simple method; it is particularly applied to those problems which is difficult to complete quantitative analysis.

The analytic hierarchy process is used to model; it is mainly carried out according to the following four steps:

(1) Establish class hierarchy model is set up; in this model, the complex problem is decomposed to parts of elements. These elements are formed several levels according to their attributes and relations. The upper level elements as a criterion will dominate related elements of next level.

(2) All the judgment matrix in the various levels is established; each time takes two factors $x_{l}$ and $x_{j}, a_{i j}$ is influence size ratio of $x_{l}$ and $x_{y}$ on $Z$, all the comparison results is expressed by matrix $\mathrm{A}=\left(\mathrm{a}_{\mathrm{q}}\right)_{\mathrm{n} \mathrm{n}_{\mathrm{n}}}, \mathrm{A}$ is $\mathrm{Z}-\mathrm{X}$ paired comparison judgment matrix (it is abbreviated as judgment matrix). It is easy to see, if $x_{l}$ and $x_{l}$ influence ration on $Z$ is $a_{j l}=\frac{1}{a_{k j}}$

(3) The level of single sorting and consistency check;

(I) Calculate the consistency index of CI, CI $=\underset{n=1}{\mathbb{a}_{\max }-\mathrm{n}}$

(II) Find the corresponding mean random consistency index $\mathrm{R}$

(iii) Calculate the consistency ratio of $\mathrm{CR}, \mathrm{CR}=\frac{\mathbb{q}}{\mathrm{m}}$

(4) The total sorts of level and consistency check. Hierarchy total sorts also require consistency check, inspection still like hierarchy total sort from the top to the lower level. This is because all levels have been carried out a single sort consistency check; the various comparison judgment matrix has been a relatively satisfactory consistency. But when comprehensively inspecting, all levels of non-consistency could still be accumulated, this results into more serious non-consistency of final analysis results.

\section{The Energy Saving Effect Evaluation Model of Energy Efficiency Power Plant}

The energy saving effect of energy efficiency power plant, we can according to the "power demand side management method", combining with the evaluation's reexpressative, effectiveness and operational requirements, the energy saving effect evaluation factors of energy efficiency power plant, they include power saving factors, environmental factors, economic factors. Electricity power saving factor include $\mathrm{CO}_{2}$ emission reductions, $\mathrm{SO}_{2}$ emission reductions, $\mathrm{NO}_{\mathrm{x}}$ e emission reductions, economic factors includes the costs and benefits.

4.1 Power saving factors

The energy saving amount of energy efficiency power plant is

\section{$\mathrm{W}=\Sigma \%_{1} W_{\mathrm{T}}$}

Where $\mathrm{N}$ reexpresss the number of contained subproject in energy efficiency power plant, $\mathrm{W}_{\mathrm{i}}$ reexpress i project energy saving amount of energy efficiency power plant.

Energy saving power of energy efficiency power plant is:

$\mathrm{P}=\sum Y_{1} R_{t}$

$\mathrm{P}_{\mathrm{i}}$ express i project energy saving power in energy efficiency power plant.

4.2 Environmental factors

Energy efficiency power plant $\mathrm{CO}_{2}$ reduction is:

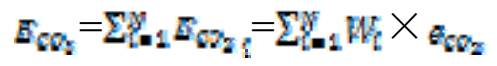

$E_{\mathrm{CQ}_{\mathrm{Y}}}$ express the i project $\mathrm{CO}_{2}$ emission reductions in energy efficiency power plant, $\epsilon_{\mathrm{CO}_{2}}$ is a conventional power plant $\mathrm{CO}_{2}$ gas coefficient, $0.997 \mathrm{~kg} / \mathrm{kWh}$ is comman

$\mathrm{SO}_{2}$ emission reduction in energy efficiency power plant is:

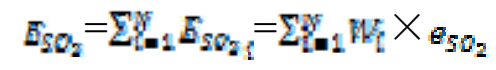


$\boldsymbol{E}_{\mathrm{SO}_{\mathbf{2}}}$ express i project $\mathrm{SO}_{2}$ emission reduction in energy efficiency power plant project, $\boldsymbol{\Xi}_{\mathrm{SO}_{\mathbf{2}}}$ is $\mathrm{SO}_{2}$ coefficient in conventional power plant, $0.03 \mathrm{~kg} / \mathrm{kWh}$ is comman

The emission reductions of energy efficiency power plant $\mathrm{NO}_{\mathrm{x}}$ is

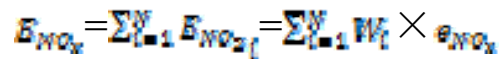

$E_{N \sigma_{\alpha \ell}}$ express $\mathrm{NO}_{\mathrm{x}}$ emission reductions of i project in energy efficiency power plant, $\bullet_{\mathrm{N} \theta_{x}}$ is $\mathrm{NO}_{\mathrm{x}}$ gas coefficient in conventional power plant, $0.015 \mathrm{~kg} / \mathrm{kWh}$ is comman

4.3 Economic factors

The cost of energy efficiency power plant project is:

$\mathrm{C}_{\mathrm{i}}$ express project investment cost of I project in energy efficiency power plant.

The benefits of energy efficiency power plant project is

$\mathrm{B}=\sum_{i=1}^{*} B_{l}$

$B_{i}$ express investment cost of $i$ in energy efficiency power plant.

4.4 Weight vector calculation

(1) Establish a pairwise comparison matrix, namely the evaluation matrix

$A=\left(a_{n j}\right)_{n=n} I, j=1,2,3 \ldots . . n$

$a_{i j}$ express sub-item $\mathrm{j}$ important extent on $\mathrm{i}$ in the factor $\mathrm{I}$, according to satty9 class scale evaluation, ask expert to mark, form a pairwise comparison matrix

(2) The various elements multiply in evaluation matrix A, and the product obtained respectively extract a $\mathrm{n}$ root, and get root value, namely:

$\left.a_{l}=\prod_{l=1}^{n+1} a_{t i}\right)^{1 / n}$

(3) $d_{i}$ will be normalized processing:

$d_{t}=d_{t} \sum_{t=1}^{n} d_{t}$

(4) Calculating eigenvalues and eigenvectors,

$\boldsymbol{\lambda}_{\max }=\sum_{i=1}^{\mathrm{n}}\left(A D^{T}\right)_{L}+\mathrm{nd}^{2}$

$\mathbf{D}=\left(d_{1}, d_{2}, \ldots \ldots a_{n}\right)$

The feature vector is the weight vector, this is D.

(5) The consistency check is done. Consistency index is $\mathrm{CI}=\left(\mathbf{M}_{\max }-n\right) /(\mathrm{n}-1)$. According to the given index in the table, $\mathrm{CI}$ and corresponding mean random consistency index RI are found. Calculate the consistency ratio $\mathrm{CR}, \mathrm{CR}=\mathrm{CI} / \mathrm{RI}$, if $\mathrm{CR}<0.1$, evaluation matrix $\mathrm{A}$ is passed consistency check. Otherwise the evaluation matrix A will be rebuilding, until the proportion of consistency meet the requirements.

\begin{tabular}{|c|c|c|c|c|c|c|c|c|c|c|}
\hline $\begin{array}{c}\text { matrix } \\
\text { order }\end{array}$ & 1 & 2 & 3 & 4 & 5 & 6 & 7 & 8 & 9 & 10 \\
\hline RI & 0 & 0 & 0.58 & 0.90 & 1.12 & 1.24 & 1.32 & 1.41 & 1.45 & 1.49 \\
\hline
\end{tabular}

4.5 Comprehensive evaluation

The model of energy efficiency power plant is comprehensively evaluated $\mathrm{H}=\mathrm{D}^{*} \mathrm{U}$, where $\mathrm{U}$ express various factors of electricity saving factors, environmental factors and economic factors. Model adopts the weighted average model of the fuzzy operation model, not only highlights the influence that main factors on the results, the effect of all factors are considered

\section{Model Test}

According to the data of the Internet, We can carry on the reasonable assumption to make the factors assessment on energy efficiency certain power plant project: 
5.1.1 Experts mark factors between the importance and form the following table:

\begin{tabular}{cccc}
\hline & Power saving factors & Environmental factors & Economic factors \\
\hline Power saving factors & 1 & 3 & 5 \\
Environmental & $\frac{1}{3}$ & 1 & $\frac{1}{4}$ \\
factors & $\frac{1}{5}$ & 4 & 1 \\
Economic factors & $\frac{1}{2}$ & & \\
\hline
\end{tabular}

5.1.2 Secondary index of factors are done evaluation and mark

(1) power saving factors

\begin{tabular}{llc}
\hline & Saving electricity amount & Saving electricity power \\
\hline Saving electricity amount & 1 & $\frac{1}{2}$ \\
Saving electricity power & 2 & 1 \\
\hline
\end{tabular}

(2) Environmental factors

\begin{tabular}{cccc}
\hline & $\begin{array}{c}\mathrm{CO}_{2} \text { emission } \\
\text { reductions }\end{array}$ & $\begin{array}{c}S \mathrm{O}_{2} \text { emission } \\
\text { reductions }\end{array}$ & $\begin{array}{c}\mathrm{NO} \mathrm{O}_{n} \text { emission } \\
\text { reductions }\end{array}$ \\
\hline $\begin{array}{c}C \mathrm{O}_{2} \text { emission } \\
\text { reductions }\end{array}$ & 1 & 2 & 4 \\
$S \mathrm{O}_{2}$ emission & $\frac{1}{2}$ & 1 & $\frac{1}{3}$ \\
reductions & $\frac{1}{4}$ & 3 & 1 \\
$N O_{x}$ emission & $\overline{4}$ & & \\
reductions & & & \\
\hline
\end{tabular}

(3) Economic factors

\begin{tabular}{ccc}
\hline & cost & benefit \\
\hline cost & 1 & 1 \\
benefit & 1 & 1
\end{tabular}

\subsection{The weight vector calculation}

Level index: $A=(0.6437,0.6437,0.6437)$

Secondary index: power saving factors: $\mathrm{B}=(0.330 .66)$

Environmental factors: $\mathrm{C}=(0.578,0.578,0.578)$

Economic factors: $\mathrm{D}=(0.50 .5)$

5.3 Through the consistency check, validate the rationality of comparison matrix.

5.4 The secondary index are synthesized, we can get $\mathrm{E}=4.4(0.21460 .0300 .12120 .12110 .2146$ 0.42910 .066 )

\subsection{Benefit equation}

First of all, according to the different data of different scale energy efficiency power plants to standardize data, combined with the weight vector of index, benefit equation are obtained:

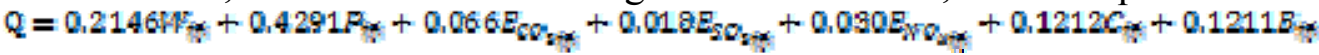

We can to evaluate good points and bad points of energy efficiency power plant project through the $\mathrm{Q}$ value, the greater the $\mathrm{Q}$, the better the nergy efficiency power plant project,.

\section{The Assessment and Promotion of Model}

\subsection{Evaluation of the model}

This article first quantify three main evaluation factors of energy efficiency power plant, energy saving amount, electricity saving power in economic factors, $\mathrm{CO} 2$ emission reductions, $\mathrm{SO} 2$ emission reductions, NOx emission reductions in environmental factors, each sub-factors usage are quantified in the costs and benefits of economic factors. After using the analytic hierarchy process (AHP) to evaluate the energy efficiency power plant, according to quadrature of different weights, importance of various factors can be understood by analyzing the results, according to the differences, the energy efficiency power plant can accurately and simply make aspect that must be focused on in 
practical cases, it is advantageous for decision of energy efficiency power plant project to produce greater benefits.

6.2 Disadvantages of the model

(1) The net loss and social benefits and other factor variables are not be considered, to ignore the impact of these factors can make the weighting factor not accurate, and exerted deviation on analysis.

(2) The relationship among each variables in the energy efficiency power plant is not fine, we can make fitting for each variable of energy efficiency power plant to make the relationship among each variable is more precise and accurate.

6.3 Promotion of the model

This model mainly used the analytic hierarchy process (AHP), the complex problems are divided into various constituent factors, and then according to dominance relationship put these factors in group form a class hierarchy. By using inter-comparison way, the relative importance of various factors is determined and evaluated; it greatly improves the scientific property effectiveness and feasibility of the evaluation. We can promote application of this model in the energy system, economic management, social science, etc.

\section{Acknowledgement}

Annual project fund of Hebei Province social science fund in 2015, project approval number: HB15YJ038

\section{References}

[1] Si Shoukui, Sun Xiqing, The mathematical model algorithm and application. National Defend Industry Press, 2011, 8, 11.

[2] Wu Mengda, Mathematical model tutorial, Higher education press, 2011.

[3] Deng Kui, The basic framework of energy consumption reversed transmission mechanism, review of economic research, 2013, 42;

[4] National Development and Reform Commission, Ministry of Industry and Information Technology, The Ministry of Finance, The electric power demand side management approach [J]. Electric power demand side management, 2010.

[5] Ramot D, Friedman M, Langholz G.Com place-fuzzy logic [J]. IEEE the Transactions on fuzzy System, 2003, 11 (4): 450-461.

[6] Peikherfeh M, Seifi H, Sheikh - E1 - Eslami M K, et al, The Optimal decision making for virtual power plant operation [C], 2011 European Energy Market. Singapore, 2010:27-29. 